\title{
$\widetilde{C}$ AGUA yTERRITORIO
}

\section{Abastecimento de água no Brasil setentrional: a gestão hídrica em Aracati (século XIX)}

\author{
Water supply in northern Brazil: hydric management in \\ Aracati (19th century)
}

\section{Abastecimiento de agua en el norte de Brasil: la gestión del agua en Aracati (siglo XIX)}

José Nilo Bezerra Diniz Universidade Federal de Santa Catarina (UFSC) Florianópolis, Brasil jnilodiniz@hotmail.com

Resumo - Entre a fonte e o consumo doméstico de água há uma rede que conecta os dois pontos. O presente artigo enfoca nos modelos de organização e gestão do serviço de abastecimento de água numa cidade do semiárido brasileiro em meados do século XIX. O crescimento urbano de Aracati, de um lado, e a incapacidade financeira municipal, de outro, permitiu a experimentação, ainda que efêmera, de um sistema de abastecimento promovido pelo capital privado. A malfadada experiência de abastecimento é uma porta de entrada para se pensar o abastecimento de água entre as demandas sociais e a especulação comercial em meados do século XIX.

Abstract - Between the water source and the domestic consumer there is a network that connects them. This paper focuses on hydrological characteristics in a semi-arid Brazilian city in the mid-nineteenth century and the technical subsidies to support the collect and the social distribution of water. Both Aracati's urban growth and the town's financial deficit allowed the tryout of a supply system financed with private money although it was a superficial experience. The frustrated experience in Aracati is the first step towards discussing the water supply among all the social demands and commercial speculations in mid-nineteenth century.

Resumen - Entre la fuente y el consumo doméstico de agua hay una red que conecta estos dos puntos. Este trabajo se centra en las características hidrológicas de una ciudad en la región semiárida de Brasil en la segunda mitad del siglo XIX y las contribuciones técnicas a la recopilación y distribución social del agua. Por un lado, el crecimiento urbano de la ciudad de Aracati y la incapacidad financiera municipal, por el otro, permitieron la experimentación, aunque efímera, de un sistema de abastecimiento promovido por el capital privado. La malograda experiencia de Aracati es el primer paso para pensarnos el abastecimiento de agua en medio de las demandas sociales y la especulación comercial en la segunda mitad del siglo XIX.

Palavras Chaves: Abastecimento de água, Cidade, Privatização, Ceará

Keywords: Water supply, City, Privatization, Ceará

Palabras clave: Abastecimiento de agua, Ciudad, Privatización, Ceará 


\section{HISTÓRIA E O ABASTECIMENTO DE ÁGUA URBANO ${ }^{1}$}

"O ponto de chegada do aqueduto é sempre a cidade, a grande esponja feita para absorver e irrigar, Nínive e seus jardins, Roma e suas termas [...]. As metáforas superficiais definem a cidade como um aglomerado de pedras, diamante facetado ou carvão fuliginoso, mas cada metrópole pode ser vista também como uma grande estrutura líquida, um espaço delimitado por linhas de água verticais e horizontais, uma estratificação de lugares sujeitos a marés e inundações e ressacas, onde o gênero humano realiza um ideal de vida anfíbia que corresponde à sua vocação profunda".

(Ítalo Calvino)

Quando o escritor Ítalo Calvino, em sua intimidade diária, gira a torneira para esquerda e vê jorrar água sobre suas mãos, imediatamente percebe que os percursos do líquido são inteiramente distintos dos caminhos naturais. Quer por meio de um complexo emaranhado de canos e tubulações, bombas e reservatórios, quer sobre o dorso das mulas que carregam os barris, as águas nos chegam como um prêmio ao esforço da cultura e não como algo que os humanos dispõem naturalmente.

As cidades são o espaço por excelência da manipulação hídrica, para onde fazem correr esse líquido passageiro, onde os humanos vivem sua condição anfíbia. A experiência de uma urbe em uma região árida ou semiárida é exemplar nesse sentido, pois demonstra como a "conquista da água" faz com que esta apareça na superfície em quantidade mais elevada e mais regular do que a natureza dispõe, fazendo da cidade um verdadeiro território das águas. Mas o acesso às águas nunca é feito de modo equânime e as formas de se apropriar desse precioso líquido estão sujeitas, se é que se pode enumerar, a três imperativos básicos: a natureza, a tecnologia e o tipo de sociedade. Sua captação e distribuição encontram balizas e limites na natureza; a técnica e tecnologia aplicada em sua domesticação são historicamente construídas e as formas sociais de se apoderar dela produzem intricadas relações de poder ${ }^{2}$.

A preocupação histórica pelo abastecimento e gestão das águas tem crescido nos últimos anos. Para além da discussão acerca da infraestrutura urbana e rural, uma literatura muito diversa no tempo e no espaço pode ser observada em diversos artigos publicados em revistas especializadas como Agua y território e Water

\footnotetext{
1 Este artigo é parte da pesquisa desenvolvida durante o mestrado intitulado "Paisagens marginais: um estudo em perspectiva histórica de localidades portuárias no sertão brasileiro (1808-1851) e no deserto do sudoeste africano (1884-1914)” no programa de Pós-Graduação em História da Universidade Federal de Santa Catarina.

2 Roche, 2000
}

history $^{3}$. Quando se fala em abastecimento de água, geralmente se evoca imagens de tubulações e dutos, bombas e torneiras que trazem o líquido distante até o uso residencial. Este artigo enfoca num sistema de distribuição outro, no qual o líquido transitava menos em calhas e canos do que por braços e tração animal.

As bases para uma história social do abastecimento de água já foram lançadas por Goubert em sua tese de doutoramento, na qual observa "a conquista da água" para a era industrial, durante os séculos XIX e XX, através da ação de médicos, engenheiros e higienistas. Já Daniel Roche em mais de um momento estudou a utilização das águas na França do Antigo Regime. O autor destacou três soluções principais para o problema de abastecimento urbano: a exploração dos recursos subterrâneos por meio de poços; a coleta direta em rios, regatos, lagoas, olhos d'água, etc.; e a captação e transporte de fontes mais distantes através de aquedutos ou canalização subterrânea. Em fins do século XVIII e no correr do XIX, o aumento de uma exigência de higiene coletiva entrou em choque com os hábitos de consumo de água. Na França, sobretudo em Paris, a coleta direta das águas fluviais foi progressivamente sendo substituídas pela canalização e não tardou para que aparecessem conflitos por parte de um grande número carregadores que se viram ameaçados pela expansão da rede de canalização ${ }^{4}$.

No Brasil, a maior referência no tema é o trabalho de Denise Bernuzzi de Sant'anna, intitulado Cidade das águas. Nessa obra, a autora analisa o antigo descompasso entre disponibilidade hídrica natural e acesso da população para a água. No Brasil, segundo a autora, "o descompasso entre abundância natural e pobreza no tratamento e na distribuição social do líquido pode ser brutal, provocando situações tão catastróficas quanto à desertificação de regiões naturalmente desprovidas de caudalosos veios aquáticos" ${ }^{5}$. A experiência da capital paulista no século XIX foi elucidativa a esse respeito, pois mesmo estando em uma região riquíssima de mananciais, córregos e no "entre rios” a população sofreu ora com a falta d'água, ora com o excesso. A questão da água potável atualmente indica o quanto a sua carência pode estar vinculada a problemas de acesso e distribuição social e não somente ao potencial hídrico disponível na natureza ${ }^{6}$.

\footnotetext{
${ }^{3}$ Matés, 2013. Tedeschi, 2014. Driaux, 2016. Thornton, 2013. Bohman, 2012.

${ }^{4}$ Goubert, 1986, 2006, 2008 e 2009. Roche, 1984 e 2000.

${ }^{5}$ Sant'anna, 2007, 294.

${ }^{6}$ Recentemente, foi notícia o caso de Mbuji-Mayi, cidade ribeirinha da República Democrática do Congo, em que a água engarrafada era mais cara que a cerveja, e como somente poucos podiam arcar com esse custo, a maioria da população sofria com a falta de água.
} 
Acreditando que ao lançar luz sobre qualquer experiência pretérita de relacionamento com a água é possível produzir uma reflexão da forma como ela é vista, tratada e utilizada no presente, busca-se aqui dialogar e contribuir com essa discussão através de um olhar em perspectiva sobre a localidade portuária de Aracati, no semiárido brasileiro.

\section{ÁGUAS POTÁVEIS E SALGADAS DE ARACATI}

A cidade de Aracati se desenvolveu nas margens do rio Jaguaribe há cerca de quinze quilômetros de sua foz (figura 1). A Vila de Santa Cruz do Aracati, fundada em 1748, surgiu do povoado "Porto dos Barcos", devido ao núcleo urbano considerável e ao desenvolvimento econômico da região, que lhe conferiu traços singulares, sendo a única vila do Siará Grande criada por motivações econômicas durante o século XVIII ${ }^{7}$. O próprio nome do povoado permite inferir a importância do rio na demarcação espacial da vila, na escolha do sítio e a importância que este iria desempenhar na dinâmica social e econômica de Aracati.

A cidade está localizada no estuário do rio Jaguaribe. Este é o espaço no qual ocorre o encontro entre água doce e salgada, tendo suas "feições resultantes da transgressão holocênica que afogou os vales dos rios.” O que o caracteriza é “a presença da ação da maré em toda sua extensão"8. O resultado da transgressão marinha sobre o leito do rio é uma configuração biótica diferente que suporta a salinidade: as matas nas áreas alagadas são de mangue, os peixes são, também, de água salgada. No caso do Jaguaribe, deve-se levar em consideração, ainda, que por ser um rio basicamente localizado no semiárido, não possuí vazão hídrica suficiente para empurrar completamente a água salgada do leito do rio nem mesmo nos meses de maior precipitação; e na estação seca o índice de água salgada chega a cerca de $90 \%$ da massa de água total no interior da calha ${ }^{9}$. Dessa forma, é necessário ressaltar a peculiaridade de Aracati do século XIX em relação a outras vilas da Província, pois, mesmo não se apropriando do rio para o abastecimento, necessitava dele de outras formas.

Não obstante a salinidade das águas na área estuarina, a presença de um solo sedimentar formado pelos grãos de areia transportados do alto e médio curso do Jaguaribe, faz com que Aracati possua um potencial hídrico subterrâneo tolerável, de modo que a vazão de

Disponível em: http://www.courrierinternational.com/article/2012/09/21/l-eaupotable-plus-chere-que-la-biere, acessado em 22 de agosto de 2012.

7 Viana Júnior, Silva, Nogueira, 2011, 83-84.

${ }^{8}$ Morais, 1996, 222.

${ }^{9}$ Dias, Marins, Maia, 2007. um poço varia de 5 a $10 \mathrm{~m}^{3} / \mathrm{h}$ nas dunas, e com média de $3,9 \mathrm{~m}^{3} / \mathrm{h}$ nos domínios sedimentares ${ }^{10}$.

A fundação da vila de Aracati à beira rio deixou marcas indeléveis nos modos dos seus habitantes se relacionarem com as águas. O fato de estar no único trecho navegável do rio Jaguaribe e mesmo assim não ter abundância de água doce em superfície foi uma questão percebida desde cedo. Quando o ouvidor geral da Capitania do Ceará, Manoel José de Farias, sugeriu a criação da vila do Aracati, em 1748, afirmou que "as agoas não são muitas, porem sam a q bastão e se lhe podem facer possos, ou cacimbas, como cá as chamão"11.

De fato, a solução levantada por esse membro da administração colonial portuguesa tem sido a principal forma de obtenção de água até os dias atuais e desempenhou um papel ainda maior no século XIX. Porém, como bem notou Sérgio Buarque de Holanda, a utilização de poços no Brasil colonial sempre foi bastante sofrível, segundo o autor:

“É certo que em sítios não muito distantes dos povoados e junto aos pousos e registros, existem já em princípios do século XIX, aguadas sofrivelmente protegidas, onde se poderia obter água fresca. Obras de administração caprichosa ou mesmo de alguns particulares, essas cacimbas não primariam pela comodidade, nem pelo asseio, nem pela salubridade. É notório que mesmo em nossas cidades coloniais mais populosas e ilustres, o estado de conservação das fontes públicas foi assunto permanente de queixas por parte dos moradores" ${ }^{\prime 2}$.

As considerações de Holanda parecem válidas em grande medida também para o caso de Aracati durante boa parte do século XIX. Havia poucas modalidades de abastecimento da urbe. Agora, estas formas serão enumeradas, pois, como observou Denise Sant'anna, cada técnica de abastecimento explorava de maneira distinta os recursos hídricos, possuía sua própria temporalidade, produzia novos gestos, criavam determinadas relações sociais, de trabalho, formas de compartilhar -mas também de se apoderar da água-, ou seja, cada uma se conectava a um modo de ver, entender e utilizá-la ${ }^{13}$

\footnotetext{
${ }^{10}$ Vieira, Feitosa y Benvenuti, 1998.

11 "Consulta do Conselho Ultramarino ao rei, sobre a necessidade de se criar uma nova vila em Aracati de Jaguaribe. Lisboa 1746, dezembro, 12”. Projeto Resgate. Documentos manuscritos avulsos da Capitania do Ceará (1618-1832). AHU_ACL_CU_017. Cx. 5. D. 304.

${ }^{12}$ Holanda, 2011, 400.

${ }^{13}$ Sant'anna, 2007.
} 
Figura 1: Elaboração de paisagens contíguas ao estuário do rio Jaguaribe



Fonte: Paula, 2006, 72.

A quase inexistência de uma engenharia hidráulica para captar a água dos poços e levá-la até as residências era suprida por outra rede que ligava estes dois pontos: trabalhadores pobres livres, mulheres e escravos com seus potes, barricas, pipas e baldes corriam de um lado a outro a fim de garantir o líquido necessário para si, ou para vendê-lo. Havia dois pontos de aguada pública na vila, que eram a Cacimba do Povo e a Travessa da Cacimba. Eles eram amiúde alvos de reclamações da população, sobretudo, por falta de cuidados com a limpeza.

No século XIX, na vila do Aracati, a estrutura de abastecimento contava com poucos pontos de coleta públicos. Todos os pontos eram supridos por águas subterrâneas, não havendo ligações hidráulicas entre as fontes. Para obter água os habitantes podiam se deslocar, por exemplo, até a fonte localizada na Travessa da Cacimba, apenas a quatro quadras da igreja matriz Nossa Senhora do Rosário e a uma da casa de Câmara e Cadeia. Ou se preferissem podiam andar até os arrabaldes da cidade e se servirem na Cacimba do Povo, na qual o líquido existia em abundância. $O$ fato de ambas as fontes serem da municipalidade, sendo o acesso a água livre e gratuita, não tornava esses espaços isentos de conflitos, disputas e favorecimentos. Além disso, muitos preferiam pagar pelo serviço de entrega domiciliar oferecido por carregadores que diariamente abasteciam as residências, seja carregando um pote ao ombro, seja transportando em carroças.

O botânico britânico George Gardner ${ }^{14}$ quando esteve em Aracati, em 1838, observou essa atividade: “a água da fonte próxima que então se consumia era vendida pelas ruas em pequenos barris, levados em carrinhos quase sempre puxados por carneiros”15. A passagem evidencia a venda de água de forma ordinária, pelo menos dentro da vila. Seu comércio não era particularidade da região. Os carregadores estavam presentes em grande número na maioria dos centros

14 George Gardner esteve no Brasil de 1836 a 1841 sob os auspícios de Willian Jackson Hooker e a serviço de diversas instituições britânicas, como a Sociedade Filosófica de Glasgow e o Royal Botanic Gardens de Kew. Percorreu a Província do Ceará no ano de 1838, desembarcando no porto de Aracati.

15 Gardner, 1975, 82. 
urbanos do Brasil oitocentista, inclusive em aglomerações imensamente maiores em número de habitantes e pontos de coleta, como Rio de Janeiro, Salvador, São Paulo e, por isso, faziam parte da paisagem urbana e, no entanto, o fato foi motivo de estranhamento para o viajante que fez questão de fazer nota sobre a atividade.
Municipal de Aracati, de 26 de setembro de 1828, quando seus vereadores discutiram sobre o estado deplorável em que se encontrava a fonte pública, necessitando "o quanto antes fazer concertar a cacimba do Povo que se acha em grande porcaria levando-lhe em conta toda a despeza do dito concerto feito" ${ }^{\prime 7}$.

Figura 2: Localização dos pontos de coleta de água potável na vila do Aracati oitocentista

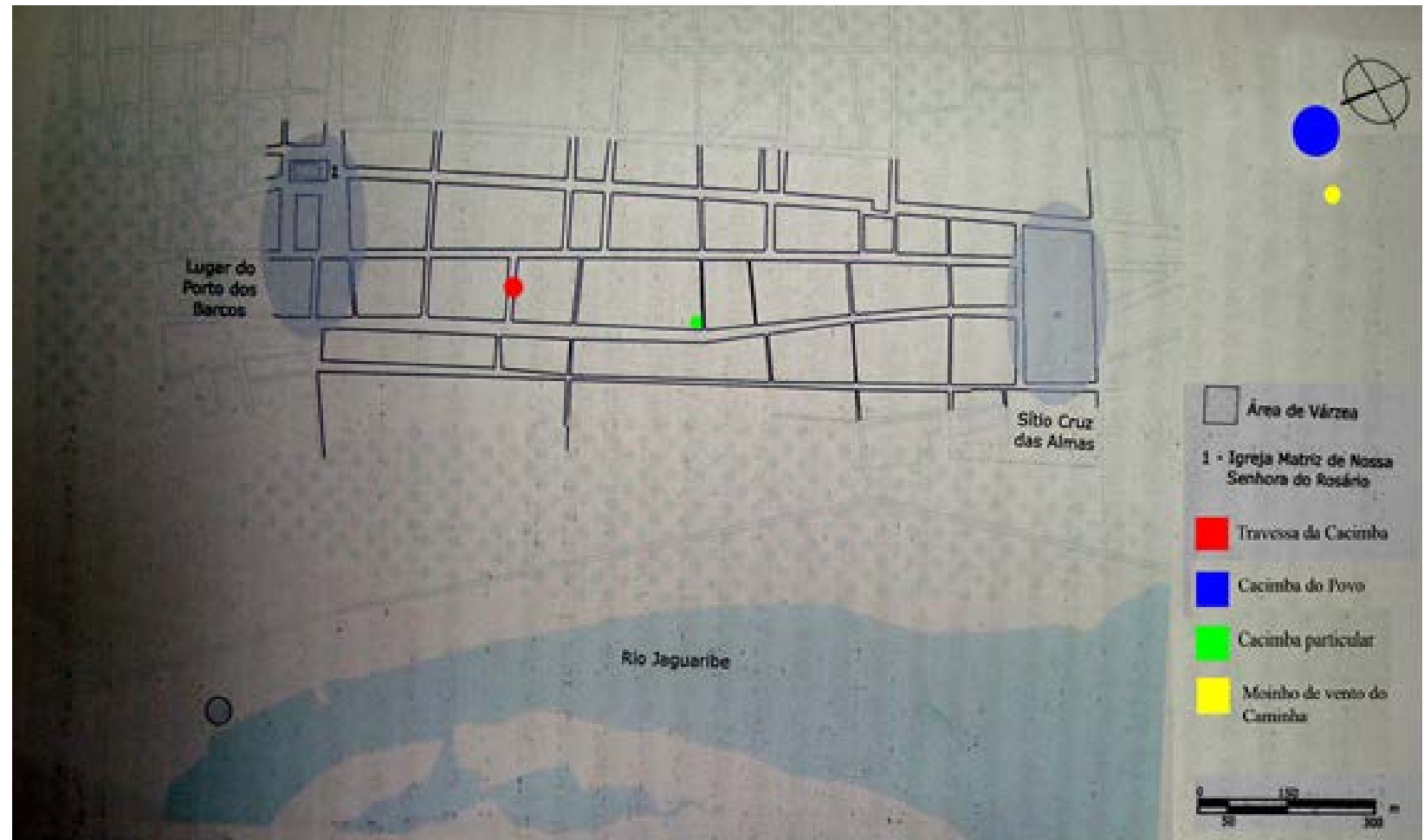

Fonte: Elaborado a partir do mapa de Jucá Neto, 2007, p. 325.

A presença dos vendedores de água, em larga medida, estava relacionada a uma conotação pejorativa que era atribuída aos pontos de coleta do precioso líquido, tendo em vista que o espaço da cacimba foi historicamente construído em torno das disputas pela água, disputada por lavadeiras, criadores de animais, viajantes, aguadeiros, transeuntes. A cacimba era um ponto fulcral na identidade de diversos trabalhadores pobres livres e cativos e, por isso, grupos mais abastados desviavam-se dela enviando seus escravos, construindo poços dentro de suas propriedades, ou pagando pelo serviço de entrega ${ }^{16}$.

O interesse em organizar e fazer melhorias nesse espaço era preocupação de grande parte da população local que sofria, sobretudo, com a falta de cuidados de limpeza. É o que pode ser percebido nas Atas da Câmara

\footnotetext{
${ }^{16}$ Um exemplo disso em Aracati era a rica família dos Caminha, que em 1859 residia de fronte à Cacimba do Povo, mas se abastecia por meio de duas cacimbas abertas na sua propriedade, não partilhando da aguada pública com os outros. Conferir Alemão 2011, 66.
}

\section{LEGISLAÇÃO E CONTROLE DO ABASTECIMENTO DE ÁGUA}

O controle e legislação dos usos das águas durante o século XIX estiveram sob responsabilidade do poder local através da criação de posturas municipais que eram posteriormente aprovadas pelas Assembleias Provinciais. Somente com o Código das Águas de 1934 (Decreto Federal 24.643 de 10/3/34) é possível falar em uma política direcionada no sentido de preservá-la, discipliná-la e aproveitá-la como um recurso econômico e energético ${ }^{18}$.

O artigo 74 do Código de Posturas de Aracati, aprovado em 12 de setembro de 1837, demonstra uma tentativa de sanar o corriqueiro problema de contaminação da água:

${ }^{17}$ APEC, Atas das sessões da câmara de Aracatide 7de julho de 1828 a 29 de julho de 1830. Ala 01; estante 03; prateleira 16; caixa 19; livro 50. Folha 9, verso.

${ }^{18}$ Corrêa, Alvim, 2000, 127. 
"A fim de conservar-se sempre com asseio a fonte pública, e evitar que malignos continuem a lançar-lhe dentro imundices criar-se-á um guarda, que vencerá a gratificação anual de cinqüenta mil réis, pagos em quartéis, o qual guarda velará continuadamente na limpeza da fonte, sob a pena de perder o equivalente de um trimestre, todas as vezes que se lhe provar desleixo e omissão no cumprimento de seus deveres" ${ }^{19}$.

O supracitado artigo das Posturas instaurou a função de guarda de cacimba, possivelmente, com o objetivo de atender as reivindicações públicas, pois a Cacimba do Povo era o principal ponto de coleta da vila. Isso é corroborado pelas atribuições necessárias. Além da questão de asseio público, a cacimba, quer pública, quer particular, necessitava de cuidados. Por ser aberta, geralmente baixa e, muitas vezes, fisicamente mal conservada, facilitava a ocorrência de acidentes, como foi o caso, em Aracati, do incidente de 24 de julho de 1881 que deu cabo da vida de um menor, filho do mestre de iate José Maria, que, “caindo dentro de uma cacimba morreu também asfixiado, vítima sem duvida da inexperiência ou descuido que acompanha a tenra idade" $^{20}$.

A criação do cargo em Aracati indica o problema de abastecimento de água e a preocupação das autoridades em conservar física e moralmente uma das únicas fontes públicas da vila. É interessante perceber que em razão da água do rio ser imprópria à ingestão, além da distância entre a vila e lagoas e olhos d'água, tornaram os poços o principal meio de abastecimento, imprescindível à vida humana. Isso reverbera na própria criação do cargo de guarda de cacimba em Aracati, que é precoce em comparação com outros municípios da Província $^{21}$.

Diacronicamente, o sistema de abastecimento da vila pouco mudou ao longo do século XIX. Ainda sobre o cotidiano em torno da fonte pública, os artigos 76 e 77 do Código de Posturas de Aracati, aprovado em $1^{\circ}$ de janeiro de 1854, indicam uma reprodução na rotina dos moradores e nas formas de utilizar o espaço. Segundo o artigo 76, o guarda “deverá conservar sempre limpo todo o edifício da fonte pública, tanto interna como externamente, tendo no possível asseio a cacimba”, além de "ter no conservatório sempre água com abundancia desde das quatro da manhã até ás dez da noite” ${ }^{22}$. Na

19 A norma afirma apenas a criação do posto de guarda da fonte. Lei $\mathrm{n}^{\circ} 68$ de 12 de setembro de 1837, artigo 74. In: Oliveira, Barbosa, 2009, tomo I, 131.

20 Ineditoriaes: Aracaty. Gazeta do Norte. Fortaleza, 13/08/1881, ano 2, 3.

${ }^{21}$ Os registros das Leis Provinciais sugerem que a função de guarda na cacimba surgiu apenas em outros municípios da Província por volta do final da década de 50 do século XIX.

${ }^{22}$ Lei $\mathrm{n}^{\circ}$ _ de 1 de dezembro de 1854, artigo 76. In: Oliveira, Barbosa, 2009, tomo II, 571. injunção, salta aos olhos a extensão do período de funcionamento da cacimba pública, que era ponto de encontro de muitos trabalhadores e escravos. Por isso, no artigo subsequente, ficava determinado que o guarda:

"não consentirá que os escravos se demorem por mais do tempo razoável, fazendo evitar por admoestações ou ameaças as algazarras e brigas que ordinariamente costumam haver entre eles [...] será obrigado morar ao pé do edifício e fonte em lugar que possa fiscalizar as pessoas que recebem água”,23.

A fonte a que a norma acima se refere foi descrita em 1859 pelo chefe da Comissão Científica de Exploração ${ }^{24}$ como sendo "um poço grande coberto e fechado, com bomba e tanques, donde saem algumas bicas”. Segundo o botânico, “a Câmara paga a um homem que tem sempre os reservatórios cheios, tocando a bomba [...] a água é fornecida grátis ao povo ${ }^{25}$.

Quanto à distribuição da água, Alemão afirma que era "vendida todas as manhãs pela cidade em barris, carregados em carros, trazendo cada carro (parece que é água) 40 barris, e os vendiam a 40 réis. Os barris são desta forma, tanto os dos carros como os que são carregados ao ombro" ${ }^{26}$.

Embora as cacimbas públicas tivessem função inconteste no abastecimento da vila, sua utilização nem sempre foi vista com bons olhos pelas autoridades locais. Além disso, não era o único meio de obter o precioso líquido. Fontes particulares, abertas geralmente nos quintais, serviam tanto para os proprietários, quanto para seus vizinhos e amigos. É o caso do poço escavado no quintal de um sobrado da rua das Flores que era pertencente à família do barão de Aracati. É escusado dizer que por meio da partilha os "donos da água” acabavam por exercer uma relação de poder assimétrica sobre os despossuídos.

A elite local exercia seu poder também através do domínio das águas. Freire Alemão observou que as de melhor qualidade da região estavam no sítio Beirada, sob o domínio de Pacheco, rico negociante de Aracati e chefe do partido Liberal na cidade. Ao visitar a propriedade, o botânico afirmou que “o que há aqui de mais notável é um olho-d’água mais perto de casa, do qual ela sai em grande quantidade e fazendo cachões [...] 
passa esta água pela melhor potável de Aracati”. A água que corria do manancial era, então, aparada em uma casa coberta com um tanque "com fundos de três palmos e com duas a três braças de quadro” e que servia de banheira $^{27}$.

Igualmente, o botânico observou na casa do senhor Caminha, chefe do partido Conservador, a existência de um pomar, "aguado por dois grandes e fundos poços, a que chamam de cacimba, com bombas de carnaúba e tiradas por moinhos de vento"; havia também "uma boa casa de banho" ${ }^{28}$. O senhor Caminha morava de fronte à Cacimba do Povo, mas abastecia-se por seus próprios meios e não se utilizava da fonte pública.

O sistema de abastecimento despertou a atenção dos membros da Comissão. José dos Reis Carvalho, que era o responsável pelos registros pictóricos, registrou em forma de aquarela o dito moinho de vento, contígua à casa de banho.

Figura 3: "Moinho de vento nos arrabaldes de Aracati, 2 de setembro de 1859. Todo fabricado de carnaúba

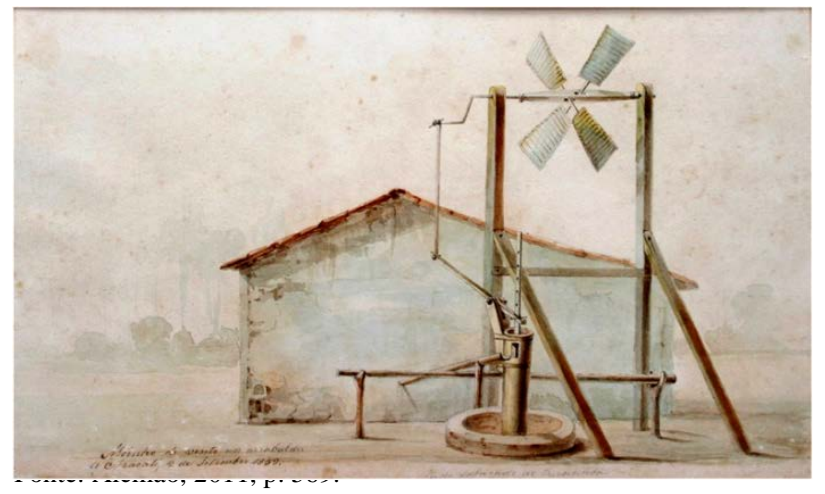

O estranhamento nos viajantes foi causado pela tecnologia utilizada na construção de tal sistema de irrigação. O chefe da expedição relata que a bomba usada para exumar a água do subsolo era "toda feita de carnaúba - esteios, travessos e bomba. O corpo da bomba, o êmbolo e válvulas tudo é de pau e tosco; mas serve”. Ela estava conectada a um moinho também inteiramente feito dessa planta e a energia utilizada para fazê-la funcionar provinha dos constantes ventos. A utilização apenas de materiais facilmente obtidos na própria região facilitava muito o conserto. O autor ainda se "admira que esta indústria não esteja mais vulgarizada na Província, onde os ventos são quase constantes, principalmente os gerais” ${ }^{29}$.

De fato, a tecnologia ficou restrita à vila; e ainda hoje é possível encontrá-los em alguns pontos da

\footnotetext{
27 Alemão, 2011, 59-60.

28 Alemão, 2011, 63.

29 Alemão, 2011, 274.
}

margem do rio Jaguaribe e no Cumbe, apenas com o incremento de algumas peças de ferro. No ano de 1884, Pompeu F. da Ponte escreveu uma série de artigos no jornal Libertador e no Cearense defendendo a difusão dos moinhos de vento pela Província. Em um deles, direcionado ao Governo Provincial e às Câmaras Municipais, centrava-se nos benefícios sociais que viriam na esteira da aplicação de tal tecnologia e solicitava ao governo a fabricação dos moinhos de vento para servirem de exemplo aos agricultores. No entender do autor, isso bastaria para aumentar a produção, garantir o aumento dos cofres públicos e fixar a população, evitando a emigração ${ }^{30}$. Em outro artigo, agora publicado nas páginas do Cearense, pregava os benefícios no que se refere a sua eficiência: “com esse sistema as águas são fornecidas com mais abundancia e com mais brevidade do que pelas antigas cacimbas, em razão de ser removida a pressão atmosférica"31. Em 1886, já é possível encontrar "bombas próprias para moinhos de vento" na João do Amaral \& e filho ${ }^{32}$. Nesse sentido, é possível afirmar que estes moinhos fabricados inteiramente de carnaúba era uma marca da paisagem heteróclita de Aracati. No entanto, não possuímos elementos para discutir a partir de quando eles foram utilizados, visto que nenhum viajante anterior a Freire Alemão fez menção a eles.

Nos idos de 1838, quando da passagem do viajante britânico George Gardner, uma nova e efêmera experiência de abastecimento foi experimentada. O estrangeiro José da Maia solicitou junto ao Governo Provincial a construção de um chafariz público na vila de Aracati em troca do privilégio exclusivo sobre a venda de água.

\section{JoSÉ DA MAIA, O SENHOR DAS ÁGUAS}

A trajetória de José da Maia é interessante para se pensar os usos das águas em meados do século XIX. Alguns de seus empreendimentos na Província do Ceará foram, em larga medida, malogrados enquanto outros nem mesmo saíram do papel. Acreditamos, porém, na importância de se investigar sobre os diferentes horizontes de possibilidades que estavam em jogo em determinada época, sobre as ideias não consumadas, sobre os projetos que não vingaram. Koselleck atenta para a importância de compreender essas expectativas passadas, ou "horizontes de expectativas" que compõe o futuro do pretérito, pois que:

\footnotetext{
${ }^{30}$ Ponte, Pompeu F. da. Libertador. Fortaleza, 30 de agosto de 1884, n $174,4$.

${ }^{31}$ Ponte, Pompeu F. da. O Cearense. Fortaleza, 23 de Agosto de 1884, $\mathrm{n}^{\circ} 88,3$.

${ }^{32}$ Libertador. Fortaleza, 30/01/1886; 5/02/1886; 8/02/1886.
} 
“considerados apenas como posições voltadas para o futuro, pode ser que elas tenham possuído apenas uma espécie de realidade psíquica. Como força motriz, no entanto, sua eficácia não é menos real do que o efeito das experiências elaboradas, uma vez que as expectativas produziram novas possibilidades às custas das realidades que se desvaneceram" 33 .

Destarte, os diferentes contratos de privilégios por ele assinados, ainda que não efetivados, permitem entrever qual o seu horizonte de expectativas e como o empresário acreditava poder lucrar com a exploração dos recursos naturais.

Nascido possivelmente em Gibraltar não se sabe ao certo quando, o estrangeiro migrou para o Brasil. Em Aracati, casou-se com uma irmã de Quintino Pamplona e Frederico Augusto Pamplona ${ }^{34}$. Este último foi um importante membro do partido Liberal, deputado provincial pela primeira vez durante biênio 1840-41, um dos fundadores do jornal $O$ cearense e, em 1853, associado a seu cunhado, tentaria criar uma linha de carros ligando Fortaleza e Icó ${ }^{35}$. Três anos depois, agora sob o pretexto de ter criado uma máquina de descaroçar algodão, José da Maia e Frederico Pamplona receberam do cofre provincial outro empréstimo de 6:000\$000 réis para fabricarem suas máquinas ${ }^{36}$. A partir do laço familiar que estabeleceu com a família Pamplona, o senhor Maia alcançou uma rede política em Aracati e na Província, obtendo inúmeros contratos de privilégio durante e depois de sua estadia no Ceará.

Segundo Guilherme Studart, José da Maia teria deixado Aracati para residir no Rio de Janeiro, onde teria se tornado professor de línguas. No entanto, a pesquisa hemerográfica leva a crer que o estrangeiro

\footnotetext{
33 Koselleck, 2006, 314.

34 Studart, 1918, 203.

35 Pelo decreto de $n^{\circ}$ 1248, de 17 de outubro de 1853, Frederico Pamplona e José da Maia receberam o privilégio exclusivo por dez anos "para em todo o Império fabricarem, venderem e importarem carros denominados -Maya- movidos por um systema de rodas de invenção do próprio suplicante”. Segundo o jornal Pedro II, no dia $1^{\circ}$ de dezembro de 1853, José da Maia e Augusto Pamplona solicitou junto a Assembleia Provincial um “empréstimo de 15:000\$000 rs afim uma linha de seus carros da capital ao Icó para o transporte de productos do centro". Dias depois, o presidente da Província, Joaquim Villela de Castro Tavares, por meio da lei $n^{\circ} 635$ de 23 de dezembro de 1853, concedeu aos empresários um empréstimo de 6:000\$000 rs (seis contos de réis) para o estabelecimento da dita linha, denominada de "carros-Maia”. Cf.: Colleção das leis do Império do Brasil de 1853. 1853, 472; Pedro II. Fortaleza: 03/12/1853, nº 1299. Lei ${ }^{\circ} 635$ de 23 de dezembro de 1853 In: In: Oliveira, Barbosa, 2009 tomo II, 387-88. Studart, 2012, 334.

${ }^{36}$ Para conhecer os termos do contrato, vide Pedro II. Fortaleza: 6 de outubro de $1857, n^{\circ} 1735,4$. No ano anterior, o empresário contraíra um empréstimo com a província de Pernambuco, mas usou como subterfúgio por não utilizar o dinheiro nas máquinas de algodão, o fato de não poder atar a bolandeira os 16 cavalos necessários para fazê-la funcionar. O Liberal Pernambucano. Recife: 21 de junho de 1856,
} ano $5, n^{\circ} 1134,3$ mudou-se para o Recife, pois, para o negócio de carros, de acordo com o jornal $O$ Cearense, Pamplona havia se “associado com seu cunhado, José da Maia, subdito britânico, residente em Pernambuco"37. Também no jornal pernambucano O Liberal Pernambucano, de 19 de janeiro de 1853, o “Sr. José da Maia [...] nesta praça é reconhecido como o primeiro mestre da língua inglesa, porque alem dos seus profissionais conhecimentos, é inglês de nação" ${ }^{38}$. Deve-se desconfiar também da sua nacionalidade inglesa, pois se assim fosse, certamente o botânico escocês George Gardner, que inclusive conheceu José da Maia, não afirmaria que o negociante Miller, com quem ficou hospedado era o único inglês de Aracati. Além disso, o estrangeiro pode ter adotado a nacionalidade inglesa para reforçar sua imagem de professor de língua inglesa perante a comunidade de Pernambuco.

Durante a residência de José da Maia em Aracati, quase todos os seus pedidos de privilégio tinham por fito, direta ou indiretamente, o domínio das águas na vila ou em alhures. A primeira concessão nesse sentido foi a construção de uma barca para atravessar o rio Jaguaribe, em 1837. Segundo a lei $n^{\circ} 92$ de 5 de outubro de 1837, ficou concedido a "José da Maia e seus herdeiros, por termo de 20 anos, o privilégio exclusivo para construir á sua custa uma barca que sirva de comoda passagem no rio Jaguaribe a qualquer hora do dia ou da noite”. O contratante deveria colocar a barca em qualquer passagem desde que ficasse nos limites vila; além disso, seria cobrada uma taxa anual de $131 \$ 000$ réis para os cofres municipais ${ }^{39}$.

Esse valor era muito superior ao imposto que ulteriormente foi cobrado sobre as canoas e as lanchas (1\$000 réis e $4 \$ 000$ réis respectivamente), que poderiam ser usadas para a travessia do rio ${ }^{40}$. Porém, era garantido ao suplicante o privilégio exclusivo sobre o transporte de pessoas, cargas e animais pelo rio. Os valores cobrados eram de 40 por pessoa a pé e 70 réis se estivesse montado, 480 por cada carro descarregado com até três juntas de boi e $1 \$ 000$ quando estivesse carregado e 40 por cada cabeça de gado vacum ou cavalar. Seriam isentos do pagamento as tropas em serviço ${ }^{41}$. Por isso, o senhor Maia acreditava ser um bom investimento, haja vista que monopolizaria o transporte entre a capital e

37 Studart, 1930, 203. O Cearense. Fortaleza: 26/07/1853, ano VII, nº 648, 2.

38 Falcão, Rodolpho Herculano Marinho. O Liberal Pernambucano. Recife: 19 de Janeiro de 1853, ano II, $\mathrm{n}^{\circ} 102,3$.

${ }^{39}$ Lei $n^{\circ} 92$ de 5 de outubro de 1837, sancionada pelo Presidente José

Martiniano de Alencar. In: Oliveira, Barbosa, 2009, tomo I, 152.

40 Artigo de $n^{\circ} 101$ do Código de Posturas de Aracati, aprovado pela lei $\mathrm{n}^{\circ} 381$ de 28 de agosto de 1846, publicada pelo Presidente Ignacio Corrêa de Vasconcellos. In: Oliveira, Barbosa, 2009, tomo I, 550.

${ }^{41}$ Lei n 92 de 5 de outubro de 1837, sancionada pelo Presidente José Martiniano de Alencar. In: Oliveira, Barbosa, 2009, tomo I, 152. 
Aracati. No entanto, ao se atentar para a arrecadação anual da câmara de Aracati nos próximos anos não está discriminada nenhuma receita proveniente da dita barca $^{42}$.

Outro empreendimento de José da Maia com vistas a dominar as águas foi a construção de uma fonte pública. A possibilidade de resolver a questão do abastecimento, inclusive no que concernia à qualidade da água consumida, veio com a proposta do estrangeiro José da Maia de dotar a cidade com um chafariz que trazia água do sítio Beirada, reputada como a fonte mais pura da cidade.

No mesmo ano em que o viajante Gardner cruzou Aracati, foi inaugurado esse chafariz, sobre o qual o botânico teceu a seguinte observação:

“Aracati quando lá estive era suprida com água de qualidade tolerável, vinda de um poço perto da cidade; mas esperava-se ter em breve um ótimo suprimento de uma fonte situada a cerca de uma légua de distância. Empenhava-se nisso um senhor Maia, natural de Gibraltar, que desde muitos anos se havia estabelecido em Aracati.

Tendo obtido uma concessão do governo, construíra um canal de tijolos para a água, mas, a nascente, estando em nível muito inferior ao da cidade, requeria uma bomba de sucção para puxar água [...] O senhor Maia esperava compensar os seus gastos com o produto da venda da água, que certamente, por sua superior qualidade obteria preferência" 43 .

É importante ressaltar que a narrativa de viagem de George Gardner foi publicada pela primeira vez em Londres em 1846, oito anos após sua passagem por Aracati e que o fato de o viajante ter inserido José da Maia e seu chafariz em suas notas de viagem e posteriormente ter considerado relevante perpetuar a informação, demonstra o estranhamento do autor em face da obra. Como bem observou Beluzzo, "as imagens dos viajantes têm o dom de evocar ausências. Promovem jogos entre o que é possível lembrar e o que se esquece, entre o que está presente e o que desapareceu. Provocam também tensões entre o visto e o enunciado. Assim, a viagem é repleta de tensões entre o que deve ser lembrado e o que se esquece” ${ }^{44}$. A reflexão da autora ajuda-nos a pensar que a literatura de viagem é, antes de tudo, um conjunto de seleções, de memória e esquecimento que constrói e transforma o que está ao seu redor em imagens, ou impressões escritas.

\footnotetext{
42 Conferir a aprovação das arrecadações anuais da Câmara de Aracat em Lei $n^{\circ} 92$ de 5 de outubro de 1837, sancionada pelo Presidente José Martiniano de Alencar. In: Oliveira, Barbosa, 2009, tomo I, 236, 323.

43 Gardner, 1975, 82.

${ }^{44}$ Belluzzo, 1996, 16.
}

José da Maia realizou uma obra de grande vulto para os padrões da Província, bem como foi o primeiro a receber uma concessão de privilégio para explorar e vender água. O canal de uma légua precisou de uma quantia considerável do investidor, além de quatros contos que pediu de empréstimo pessoal a José Martiniano de Alencar ${ }^{45}$. Para se ter uma ideia do que representava esse montante, as despesas autorizadas pela Assembleia provincial para a Câmara de Aracati no ano corrente de 1837 era de 1:589\$990, incluindo a manutenção das obras públicas ${ }^{46}$. Talvez por isso tenha vencido o esquecimento que aplacou muitas outras reminiscências de Gardner.

A lei de $n^{\circ} 33$ de 05 de outubro de 1837, aprovada pelo Presidente da Província José Martiniano de Alencar, concedeu a José da Maia o privilégio de construir um chafariz que traria a água da Beirada, região distante da urbe, na qual se localizava um notável olho d’água. O senhor Maia acreditava ser possível tornar a água um negócio rentável devido à qualidade superior do produto que dispunha ao público. De fato, a água que seria fornecida por sua fonte era tida como a melhor de toda a região por ser proveniente de uma fonte térmica. Vale ressaltar que a construção do chafariz era uma iniciativa particular, por meio da qual José da Maia recebia privilégio, e não um projeto de abastecimento de água público. Devido à demanda urbana, sistemas públicos já existiam pelo menos desde o século XVIII no Rio de Janeiro, São Paulo e na região mineira (Mariana e Vila Rica) ${ }^{47}$.

A assinatura do contrato com o estrangeiro, no entanto, previa uma nova forma de se relacionar com a água, à medida que lhe atribuía um valor venal. De acordo com o primeiro artigo, o empresário se comprometia “a construir a sua custa um Chafariz na Vila do Aracati, fazendo encanar para ele as Águas da Beirada, por um cano por baixo do chão, feito de tijolo de barro cozido, para melhormente conservarem as águas a sua salubridade”. O barro cozido era um material apreciado em sistemas subterrâneos desde a Antiguidade Clássica por ser de fácil conserto e preservar a salubridade e sabor da água ${ }^{48}$. Ao passo que para a construção de calhas abertas os moradores da vila privilegiavam o tronco da carnaúba, extraído localmente.

Além disso, era obrigação do contratante “[art. $2^{\circ}$ ] fornecer com abundancia a água que for necessária para

\footnotetext{
45 Carta de José da Maia endereçada a José Martiniano de Alencar em 5 de abril de 1838. In: Anais da Biblioteca Nacional. Correspondência Passiva do Senhor José Martiniano de Alencar. Vol. 86. Rio de Janeiro: 1966, 434- 435.

${ }^{46}$ Oliveira, Barbosa, 2009, tomo I, 149

${ }^{47}$ Tedeschi, 2014. Sant'anna, 2007, Santos, 1940.

48 Tedeschi, 2014, 13.
} 
o consumo do Povo da Vila”. É escusado dizer que o "povo da vila” significava apenas aqueles que poderiam pagar pelo consumo da água, excluindo os pobres, que era grande parte dos moradores ${ }^{49}$. Em contrapartida, José da Maia receberia o "privilegio de só ele vender [água] dentro da Vila, por espaço de trinta anos”. O valor seria "de vinte réis por cada pote, ou balde em uso hoje em dia”, estando isentas da taxa apenas as embarcações do Estado e, em caso de incêndio, as águas necessárias para extinguir o fogo ${ }^{50}$.

O empreendimento instaurava uma nova relação com a água, abrindo um novo campo de possibilidades à exploração do recurso. Até então o líquido era gratuito, ficando a cargo de cada um o modo de obtê-lo. Aqueles que podiam pagar pelo serviço optavam por receber água em suas habitações, havia também os que possuíam cacimbas no quintal ou tinham uma relação amistosa com o dono de uma. Já outros, estes desafortunados, carregavam pessoalmente seus barris. Com a construção do chafariz, entretanto, um valor pecuniário recaía sobre a água, transformando-a em mercadoria.

Em contrapartida, surgia uma nova relação de poder com essa configuração de acessibilidade à água. Diferente da coleta em fontes privadas, como pequenos açudes, ou cacimbas, onde os proprietários arrogavam para si diversas prerrogativas, inclusive de interesses políticos, e controlavam rigorosamente quem estava autorizado ou não a pegar água, o novo acesso ao líquido era pautado por uma relação impessoal, pois a obrigação do concessionário era fornecer água suficiente para todos da vila, melhor dizendo, todos que pudessem pagar por ela.

Não obstante, o empresário teve uma série de dificuldades de fazer vingar seu empreendimento. Ainda na fase de construção, percebeu que seria necessário bombear a água até o nível da vila ${ }^{51}$. Depois, com a maior parte da obra já realizada, em abril de 1838, teve seu empréstimo com banco cortado, faltando-lhe recursos para concluir a fonte ${ }^{52}$. Depois de concluída a fonte, o empreendimento fracassou por questões de ordem social e ambiental. Social, porque o senhor Maia não conseguiu recuperar o dinheiro investido, uma vez

49 B. C. D., Termo de Condições que assigna Jozé da Maia, emprezario da obra de huma Fonte Publica na Vla do Aracati. In: Ceará. Registro de Diversos Termos. 1837-1856. Fortaleza: Encadernadora Tupi, 1979, f. 6.

${ }^{50}$ B. C. D., Termo de Condições que assigna Jozé da Maia, emprezario da obra de huma Fonte Publica na $\mathrm{Vl}^{\mathrm{a}}$ do Aracati. In: Ceará. Registro de Diversos Termos. 1837-1856. Fortaleza: Encadernadora Tupi, 1979, f. 6.

51 Gardner, 1975, 82

52 Carta de José da Maia endereçada a José Martiniano de Alencar em 5 de abril de 1838. In: Anais da Biblioteca Nacional. Correspondência Passiva do Senhor José Martiniano de Alencar. Vol. 86. Rio de Janeiro: 1966, 435. que a maioria continuou a coletar a água das fontes públicas gratuitas. Ambiental, porque o canal feito de tijolo de barro foi destruído na enchente de 1839.

Assim, José da Maia, que somente lograra concluir a obra por meio de empréstimo, sentiu-se obrigado a abandonar o empreendimento e, conseqüentemente, abriu mão do privilégio da venda de água pelo prazo de vinte anos. Nenhum outro projeto da mesma natureza foi desenvolvido na cidade durante o século XIX e primeiras décadas do XX. Mesmo Fortaleza, principal cidade da província, só passou a contar com um sistema de distribuição de água por canos em 1867 -administrado pela Ceará Water Company-.

Na capital da província, as chuvas de 1839 também destruíram o recém inaugurado chafariz do Largo do Palácio, cujas estruturas não foram igualmente reparadas. Porém, a demanda crescente por um sistema de abastecimento possibilitou a construção de uma nova rede de chafarizes na década de 60 do mesmo século, financiada pelo capital privado ${ }^{53}$.

Em Fortaleza, foi inaugurada em 1867 a Ceará North Brazil Company Water Works Limited, de capital inglês. A empresa formada na Inglaterra em 1865 recebeu o monopólio de distribuição de água em Fortaleza por meio do encanamento das águas dos chafarizes do Bemfica. O contrato celebrado entre a empresa e o governo provincial estabelecia que além do encamento do Bemfica, a companhia era obrigada a vender água em carroças por toda a cidade. O valor a ser cobrado pelo caneco de 20 litros era de 40 réis, o dobro do valor determinado em Aracati para José da Maia, mas semelhante ao preço do barril vendido nesta urbe ao tempo da passagem de Freire Alemão ${ }^{54}$. Durante a inauguração, o jornal A Constituição comenta que:

“O Ceará sentia-se desta necessidade urgente, e a câmara municipal de 61 empenhou-se em remedial-a pedindo aos engenheiros Bastos, Barbosa e Herbster um plano e orçamento para encananal-a de Jacaracanga para esta cidade.

Abortou este projecto por ser o orçamento superior as forças da municipalidade, e não encontrar ella recursos para realisal-a. Então vingou a idéa no Sr. José Paulino Hoonholtz que obteve da assembléa a concessão e privilegio para este fim que acaba de realiiar e por que o felicitamos, assim como a todos aquelles que o auxiliaram associando-se" 55 .

A citação é clara quanto à relação entre implantação de serviço urbano e capital privado na capital provincial do Ceará. A transferência dos custos de instalação da

\footnotetext{
53 Maia Neto, 2014.

54 Maia Neto, 2014, 154.

55 “O Progresso”. A Constituição, 28 Mar de 1867, 1-2. In: Maia Neto, 2014, 126.
} 
infraestrutura de abastecimento de água potável para empreendedores privados, por meio de concessões monopolistas indica uma escolha política da gestão pública na partilha social do líquido semelhante em ambas as cidades do Ceará. Assim como em Aracati, o exclusivismo da Ceará Water Company resultava no fechamento de aguadas públicas, cacimbas e chafarizes, limitando a atuação dos aguadeiros na cidade. A empresa atuou regularmente até o esgotamento das águas dos poços Bemfica durante a seca de 1877, período em que foi suspenso o seu monopólio. Uma nova experiência de abastecimento de água encanada somente seria retomada cerca de 30 anos depois ${ }^{56}$. É interessante notar que tanto em Aracati quanto em Fortaleza, o malogro do abastecimento foi resultado de interações sociais, técnicas e ambientais. Se na capital cearense a falta de água durante a seca impediu as pretensões monopolistas da Ceará Water Company, em Aracati foi seu excesso que frustrou os planos de José da Maia.

\section{CONCLUSÕES}

O abastecimento de água potável no Aracati oitocentista foi moldado face às condições ambientais estuarinas, favorecendo a exploração subterrânea das águas como a principal forma de coleta. Entretanto, a prática abarcava diferentes modos de recolher e transportar o líquido, incluindo carregadores, poços, bombas d'água, fiscais de cacimba, moinhos de vento e um chafariz de água canalizada. Cada forma criava uma configuração social e uma relação socioambiental distintas, remodelando noções de valor da água, de consumo e de desperdício. Estas vicissitudes ficam muito claras quando comparamos as duas formas de uso das águas do manancial do sítio Beirada empregadas no século XIX: José da Maia vislumbrou-as como um recurso valioso e tentou aproveitá-las para seu projeto de chafarizes, precificando a água a cada barril coletado; posteriormente, a mesma fonte em posse da família Pacheco era usada com finalidades dramaticamente distintas, envolvendo a irrigação do pomar e o abastecimento da casa de banho.

Apesar da existência de fontes de coleta particulares, como o poço da residência do barão de Aracati e o moinho de vento da casa do senhor Caminha, a maior parte da população dependia sensivelmente das fontes públicas para as suas necessidades. O cuidado sobre esses dois pontos públicos levou a uma precoce legislação e regulamentação do uso das aguadas e do seu espaço se comparados a outras vilas da província.
Por fim, podemos observar que nas duas principais cidades da Província do Ceará, as primeiras infraestruturas do serviço de abastecimento de água encanada foram criadas e geridas por empresas ou capital privado. Fenômeno semelhante foi observado por Matés-Barco em grandes cidades da Europa ${ }^{57}$. Porém, a transição de um abastecimento domiciliar realizado por aguadeiros com seus potes, barricas e carroças para um sistema de captação e distribuição de água tubular não ocorreu com a primeira experiência ensaiada por José da Maia, mas se deu com desconfianças e descontinuidades. O processo histórico que culminou na aceitação do suprimento domiciliar de água foi produzido lentamente e constituído de avanços e recuos. Por isso, ainda hoje ambas as modalidades coexistem em Aracati, sendo possível observar a faina dos carregadores. Os poços e cacimbas abertas deram lugar a cinco dessalinizadores públicos, nos quais é possível observar intensa atividade de carregadores transportando recipientes em carroças puxadas pela tração animal ou por motos.

\section{FonTES CONSULTADAS}

Relatórios de Presidente de Província (1836-1860). Disponível em: http://www.crl.edu/brazil/provincial/ceará.

Biblioteca Nacional Digital Brasil.

A Constituição (1863-1889).

Gazeta do Norte (1880-1890).

O Cearense (1846-1891).

O Liberal Pernambucano (1850-1859).

Pedro II (1840-1889).

Libertador.

Arquivo Público do Estado do Ceará (APEC - fontes manuscritas).

Atas da Câmara Municipal de Aracati (1828-1830). Ala 01, estante 03, prateleira 16, caixa 19 e livros 50 e 53.

Ofícios expedidos a diversas autoridades (1838-1853). Ala 02, estante 02 , prateleira 10 , caixa 93 , livro $\mathrm{S} / \mathrm{N}$.

Quadro de Recitas e Despesas de 1863. Ala 02, estante 02, prateleira 10, caixa 93. Livro S/N.

Oliveira, A. L.; Barbosa, I. C. 2009: Leis Provinciais: Estado e Cidadania (1835-1861). Fortaleza, INESP, 3 tomos.

Anais da Biblioteca Nacional. 1966: Correspondência Passiva do Senhor José Martiniano de Alencar. Rio de Janeiro.

Gardner, G. 1975: Viagens ao interior do Brasil, principalmente nas províncias do Norte e distritos do ouro e dos diamantes durante os anos de 1836 - 1841. Belo Horizonte; São Paulo, Editora Itatiaia; Editora USP.

\footnotetext{
${ }^{56}$ Maia Neto, 2014, 131.
}

${ }^{57}$ Matés-Barco, 2013. 
Studart, G. 2012 [1891]: Dicionário bio-bliográphico cearense. Edição fac-símile. Fortaleza, Iris, Secult, Vol. 1.

Studart, B. 1921: Estrangeiros e o Ceará. Revista do Instituto Histórico do Ceará. Fortaleza, Tomo XXXV.

Studart, B. 1918: Estrangeiros e o Ceará. Revista do Instituto Histórico do Ceará. Fortaleza, Tomo XXXII.

Alemão, F F. 2006: Diário de Viagem de Francisco Freire Alemão: Fortaleza-Crato, 1859. Fortaleza, Museu do Ceará, Secretaria de Cultura do Estado do Ceará.

\section{BIBLIOGRAFÍA}

Belluzzo, A. M. 1996: "A propósito d’o Brasil dos Viajantes", Revistausp, 30, 10-19. http://dx.doi.org/10.11606/issn.23169036.v0i30p6-19.

Bohman, A. 2012: "The presence of the past: a retrospective view of the politics of urban water management in Accra, Ghana", Water History, 4(2), 137-154. http://dx.doi.org/10.1007/s12685-011-0047-2.

Brasil 1853: Colleção das leis do Império do Brasil de 1853. Rio de Janeiro, Typographia Nacional, Tomo XIV.

Braga, R. 2004: História da Comissão Científica de Exploração. Fortaleza, Demócrito Rocha.

Corrêa, D. S; ALVIM, Z. M. F. 2000: A água no olhar da história. São Paulo: Secretaria de Meio Ambiente.

Dias, F. J. S. 2007: "Hidrodinâmica das descargas fluviais para o estuário do Rio Jaguaribe (CE)”. Dissertação de Mestrado, Universidade Federal do Ceará, Fortaleza.

Dias, F. J. S; Marins, R. V; Maia, L. P. y Farias, E. G. G. 2007: Dependência do tempo de residência da água no estuário do rio Jaguaribe (ne, brasil), em relação à entrada de águas marinhas e a descarga de água doce. Florianópolis, XII Congresso LatinoAmericano de Ciências do Mar (XII COLACMAR).

Driaux, D. 2016: "Water supply of ancient Egyptian settlements: the role of the state. Overview of a relatively equitable scheme from the Old to New Kingdom (ca. 2543-1077 BC)", Water History, 8 (1), 43-58. http://dx.doi.org/10.1007/s12685-015-0150-x.

Goubert, J. P. 1986: La Conquête de l'eau. L'Avènement de la santé à l'âge industriel. Paris, Laffont.

Goubert, J. P. 2008: Une histoire de l'hygiène. Eau et salubrité dans la France contemporaine. Paris, Hachette, col. Pluriel.

Goubert, J. P. 2006: "L'eau et le changement entre transcendance et réalités. Le cas de la France”, en Gélard, J-P. (org.): L'eau, source de vie, source de conflits. Reno, Presses universitaires de Rennes, 7-72.

Goubert, J. P. 2009: “A conquista da água na era industrial”, en Serres, J. C. P. y Schwartsmann, L. B. (Orgs.): História da Medicina. Instituições e práticas de saúde no Rio Grande do Sul. Porto Alegre, EDIPUCRS.
Holanda, S. B. 2011: Sérgio Buarque de Holanda: escritos coligidos, livro1, 1920-1949. São Paulo, UNESP, Fundação Perseu Abramo, Organização de Marcos Costa.

Jucá Neto, C. R. 2007: “A urbanização do Ceará setecentista: As vilas de Nossa Senhora da Expectação do Icó e de Santa Cruz do Aracati”, Tese (Doutor), Curso de Arquitetura e Urbanismo, Departamento de Faculdade de Arquitetura, Universidade Federal da Bahia, Salvador.

Lemenhe, M. A. 1993: Expansão e hegemonia urbana: o caso de Fortaleza. Fortaleza, UFC

Lemenhe, M, A. 1991: As razões de uma cidade: conflito de hegemonias. Fortaleza, Stylus Comunicações.

Maia Neto, E. F. 2014: "O Abastecimento de água em Fortaleza-CE (1813-1867)”, Espacialidades, 7, 96-113.

Matés-Barco, J. M. 2013: "La conquista del agua en Europa: los modelos de gestión (siglos XIX y XX)”, Agua y territorio 1, 21 29, http://dx.doi.org/10.17561/at.v1i1.1030.

Morais, J. O. 1996: "Processos de Impactos Ambientais em Zonas Costeiras. Geologia do Planejamento Ambiental”, Revista de Geologia da UFC, 9, 191-242.

Paula, D. P. 2006: "Elaboração de Paisagens contíguas ao estuário do rio Jaguaribe-CE”, Dissertação Mestrado em Geografia, Universidade Estadual do Ceará, Fortaleza.

Roche, D. 2000: História das coisas banais: nascimento do consumo nas sociedades do século XVII ao XIX. Rio de Janeiro, Rocco.

Roche, D. 1984: "Le temps de l'eau rare du Moyen Âge à l'époque moderne”, Annales Économies, Sociétés, Civilisations, 39(2), 383399, http://dx.doi.org/10.3406/ahess.1984.283062.

Sant'anna, D. B 2007: Cidade das águas: usos de rios, córregos, bicas e chafarizes em São Paulo (1822-1901). São Paulo, Senac São Paulo.

Tedeschi, D. M. R. 2014: "O caminho das águas na América Portuguesa: a rede de abastecimento de Mariana no século XVIII", Agua y territorio, 3, 10-17, http://dx.doi.org/10.17561/at.v1i3.1418.

Thornton, J. 2013: "Bristol Water Works Company; a study of nineteenth century resistance to local authority purchase attempts", Water History, 5(3), 307-330, http://dx.doi.org/10.1007/s12685-0130083-1.

Vieira, T. V.; Feitosa, F. A. C. y Benvenuti, S. M. P. (Orgs.) 1998: Programa de Recenseamento de Fontes de Abastecimento por Água Subterrânea no Estado do Ceará: Diagnóstico do município de Aracati. Fortaleza, Diretoria de Hidrologia e Gestão Territorial Residência de Fortaleza. 